\title{
Entre el compromiso y la privacidad. Memorias de guerra y exilio de mujeres y hombres
}

\author{
Mónica Moreno Seco y Alicia Mira Abad \\ Profesoras titulares. Universidad de Alicante

\section{Between political commitment and privacy. Female and male memories of war and exile}

\begin{abstract}
RESUMEN
Las memorias de los exiliados y exiliadas españoles, de diversa procedencia política, como republicanos, anarquistas o comunistas, constituyen un testimonio de lucha en defensa de la democracia. En ellas la privacidad ocupa un segundo plano que, dependiendo del autor/a, se desarrolla en mayor o menor medida. Aunque perviven los estereotipos de género, el compromiso político en este contexto difumina una separación rígida entre esferas de actuación masculinas, supuestamente públicas, y femeninas, circunscritas al hogar y la maternidad. Otros factores como la edad, el grado de vinculación política o el peso de valores éticos vinculados a la izquierda contribuyen a matizar comportamientos.
\end{abstract}

PALABRAS CLAVE Memoria, Guerra Civil, exilio, género, esfera pública y privada, compromiso político.

\section{ABSTRACT}

The memories of the Spaniards exiled, from diverse political origins, such as republicans, anarchists or communists, make up a proof of the democratic fight. In them, privacy is pushed into the background and, depending on the author, it is developed to a greater or lesser extent. Although the stereotypes about genre remain, the political commitment in this context blurs a rigid separation between male spheres of actuation (supposedly public) and female ones (restricted to motherhood and domesticity). Other factors, such as the age, the degree of political links or the weight of the ethic values linked with the left, contribute to qualify behaviours.

KEY WORDS

Memory, Spanish Civil War, exile, genre, public and private sphere, political commitment. 


\section{INTRODUCCIÓN}

El objetivo fundamental de este trabajo es reflexionar sobre la pluralidad de experiencias de la Guerra Civil y el exilio y la diversidad de representaciones de dichas vivencias en las memorias escritas, poniendo de relieve la convivencia entre lo público y lo privado, entre compromiso político y vida cotidiana. Después de la derrota de 1939 miles de hombres y mujeres tuvieron que abandonar España pero continuaron identificándose con la causa republicana y por ello desearon dejar testimonio de sus vidas y de su labor política ${ }^{1}$. Estos testimonios escritos se constituyeron en la proyección pública de una memoria colectiva del exilio que se consideraba necesario hacer perdurar, para evitar el olvido, expresando una clara "voluntad de recuerdo ${ }^{2}$. Muchas de las autobiografías analizadas pretenden ser «memorandum de lo que fue un pueblo en éxodo para los que aguardaban en la tierra en la que se censuraba la memoria» ${ }^{3}$. A diferencia de los testimonios orales, la memoria escrita arroja un discurso ordenado ${ }^{4}$, que obedece a una intencionalidad política o moral. Hay que tener en cuenta que los relatos constituyen una «puesta en escena» consciente o inconsciente, una «autorrepresentación ejemplar ${ }^{5}$, ya que en el discurso biográfico no se observa una verdadera evolución sino que las ideas preconcebidas pautan toda la narración 6 . Por otro lado, en las memorias se entrelazan constantemente vivencias personales y acontecimientos políticos, lo cual supone un problema para discernir la forma en que el autor o la autora conjuga lo subjetivo y lo objetivo, o si se prefiere cómo moverse entre psicología e historia ${ }^{7}$. El punto en común en todos los testimonios analizados es la disidencia política y la experiencia de la confrontación bélica y la huida. Pero existen grados en el compromiso político en su cruce con las vivencias personales, tanto entre mujeres como entre hombres.

Aunque las memorias masculinas son más conocidas que las femeninas ${ }^{8}$, estas últimas ya comienzan a ser investigadas, gracias a los trabajos de Mangini, Di

1 Se calcula que los hombres representaron el $57 \%$ y las mujeres el $43 \%$ del colectivo de exiliados (CASTELLS, I.: «Los exilios políticos en la España contemporánea», Ayer, 67 (2007), p. 266). Una visión de conjunto sobre las exiliadas en ALTED VIGIL, A.: «Mujeres españolas emigrantes y exiliadas. Siglos XIX y XX», Anales de Historia Contemporánea, 24 (2008), pp. 59-74. Unas primeras aproximaciones a las experiencias de las exiliadas en ALCALDE, C.: Mujeres en el franquismo. Exiliadas, nacionalistas y opositoras. Barcelona, Flor del Viento, 1996 y RODRIGO, A.: Mujer y exilio, 1939. Madrid, Compañía Literaria, 1999.

2 MARTÍNEZ, J.: Exiliadas. Escritoras, Guerra Civil y memoria. Barcelona, Barcelona, 2007, pp. 17-21.

3 TORRES NEBREA, G.: «Introducción» en LEÓN, M.T.: Memoria de la melancolía. Madrid, Castalia, 1999, p. 46.

4 DOMÍNGUEZ PRATS, P.: De ciudadanas a exiliadas. Un estudio sobre las republicanas españolas en México. Madrid, Fundación Largo Caballero-Cinca, 2009, p. 27.

5 DI FEBO, G.: «Memorialistica dell'esilio e protagonismo femmenile degli anni Trenta» en DI FEBO, G. y NATOLI, C. (eds.): Spagna anni Trenta. Società, cultura, istituzioni. Milán, Franco Angelli, 1993, p. 378.

6 PASSERINI, L.: Le fonti orali, la memoria. Firenze, La Nuova Italia, 1988, p. 9.

7 Ibidem.

8 Entre otras razones, porque los mitos de Dolores Ibárruri y Federica Montseny borraron el recuerdo de otras muchas mujeres que tuvieron protagonismo político y escribieron sus memorias (TAVERA, S.: «La memoria de las vencidas: política, género y exilio en la experiencia republicana», Ayer, 60 (2005), p. 201). 
Febo, Tavera o Josebe Martínez. Como indica Castells, «con sus escritos, estas mujeres se convierten en sujetos visibles de la historia oculta de este grupo: rescatan sus recuerdos para integrarlos a la memoria de su colectivo" ${ }^{9}$. Grillo apunta que el género autobiográfico siempre ha estado vinculado al hombre. Las mujeres se han hecho visibles en él recientemente, pero se encuentran ante la disyuntiva de «limitarse al mundo íntimo y privado como el hogar, la familia, etc...» 0 «'copiar' el modelo 'masculino' de la autobiografía tradicional, trazando un recorrido lineal de una vida pública y de una afirmación individual, [haciendo] de la literatura un arma de denuncia, de lucha y de afirmación de la diferencia» ${ }^{10}$. Josebe Martínez cree que frente a la memoria política, compacta, de los autores exiliados, que suponen una respuesta al franquismo, los escritos de las exiliadas remiten más a una memoria de episodios personales, aunque cita la autobiografía de Isabel Oyarzábal, I Must Have Liberty, como un texto que contradice los cánones al tratar sobre todo la faceta pública de la autora ${ }^{11}$.

Este trabajo pretende matizar la identificación estereotipada entre memorias masculinas, que se centran sólo en la vida pública, y memorias femeninas que únicamente describen sentimientos y hechos de la vida familiar. Si por lo general las autobiografías femeninas enfatizan los aspectos personales sobre los políticos, en España esta relación se invierte, pues las memorias escritas de mujeres comienzan con el exilio, tras el acceso a la ciudadanía política y «la apropiación de la palabra» durante la República y la guerra ${ }^{12}$. Las exiliadas desean que sus escritos se conviertan en testimonio colectivo, en defensa de la causa republicana durante el conflicto y el largo exilio ${ }^{13}$. A pesar de la heterogeneidad que presentan las mujeres que emprendieron el éxodo de $1939^{14}$, provenían de un ambiente politizado del que con frecuencia fueron partícipes, como sucede entre aquellas que escribieron sus memorias ${ }^{15}$. Estas mujeres deseaban proyectar en sus escritos autobiográficos un

9 CASTELLS, I.: Op. Cit., p. 269.

10 GRILLO, R.M.: «Juegos de parejas en un espejo. Masculino y femenino en la escritura autobiográfica del exilio» en BALCELLS, J. M. y PÉREZ BOWIE, J. A. (eds.): El exilio cultural de la Guerra Civil (1936-1939). Salamanca, Ediciones Universidad Salamanca, 2001, pp. 324-326.

11 MARTÍNEZ GUTIÉRREZ, J.: «Hegemonía intelectual, exilio y continuidad histórica» en AZNAR SOLER, M.: El exilio literario del 39. Barcelona, Gexel, 1998, vol. I, p. 330 y MARTíNEZ, J.: Exiliadas..., pp. 36 y 132.

12 DI FEBO, G.: «Memoria e identidad política en los escritos autobiográficos femeninos del exilio» en ALTED, A. y LLUIS, M. (eds.): La cultura del exilio republicano español de 1939. Madrid, UNED, 2003, vol. 2, p. 305.

${ }_{13}$ MANGINI, S.: «Memories of Resistance: Women Activists from the Spanish Civil War», Signs, 17:1 (1991), pp. 172-173.

14 Muchas mujeres que salieron por la frontera francesa en 1939 huían por miedo a los bombardeos y a la represión, o acompañando a sus familiares, es decir, no todas eran exiliadas políticas en sentido estricto (ALTED VIGIL, A.: La voz de los vencidos. El exilio republicano de 1939. Madrid, Aguilar, 2005, pp. 42-43).

${ }^{15}$ No puede olvidarse que además de su militancia política y sindical, muchas de ellas se vincularon a la Unión de Mujeres Españolas, heredera de la Agrupación de Mujeres Antifascistas de la Guerra Civil, o a Mujeres Libres, que continuó en el exilio. Para la actividad política de las mujeres en la guerra, remitimos a NASH, M.: Rojas. Las mujeres republicanas en la Guerra Civil. Madrid, Taurus, 1999. Para sus actividades en Francia, vid. YUSTA, M.: Madres Coraje contra Franco. La Unión de Mujeres Españolas 
modelo de mujer militante, autónoma, alejada del estereotipo femenino centrado en el hogar y en la familia, pero que no se ajustaba tampoco a una conciencia feminista. Lo cual no significa que no puedan encontrarse algunos matices. Al confrontar las memorias femeninas con los testimonios escritos por hombres, Mangini constata diferencias, pues las primeras abordan aspectos como la prostitución o los embarazos, que no aparecen en las memorias de los varones ${ }^{16}$. Pero, en términos generales, la escritura se convirtió para los exiliados y exiliadas en una forma de militancia ante el silencio y el olvido, por encima de los sentimientos ${ }^{17}$.

En el mismo sentido, Grillo ha centrado su análisis en las memorias de parejas de intelectuales y llega a la conclusión de que hombres y mujeres pretenden resaltar su vida pública por encima de cualquier otro aspecto, aunque se aprecian disparidades en la forma de expresarlo ${ }^{18}$. Sucede algo similar entre militantes de partidos y sindicatos. En El único camino, Dolores Ibárruri destaca la intención de proyectar su carrera política dejando en un plano muy secundario su vida privada, que sólo describe antes de su implicación en la política. Por su parte, Federica Montseny también presenta una imagen de una mujer fuerte, coherente políticamente, capaz de continuar la lucha incluso en los momentos más difíciles y de desánimo. No obstante, lo hace de una forma menos aséptica y entrelazando lo público y privado ${ }^{19}$.

Sin embargo, ese deseo de proyectar una trayectoria política firme es matizado con mayor o menor intensidad por el contexto histórico, las circunstancias familiares y el género. La incidencia de este último factor dependerá evidentemente del grado de identificación con los estereotipos establecidos ${ }^{20}$. En algunos casos, las propias autoras consideran su escritura de menor entidad respecto a la obra masculina. En el prólogo de sus memorias, Carmen Parga, militante de las JSU y exiliada en el bloque comunista, las califica como «una versión femenina de un episodio de la gran aventura vivida por los españoles que perdimos la guerra y fuimos lanzados al exilio exterior», escritas "sin la preocupación del rigor científico o histórico» ${ }^{21}$. Al compararlas con las que publicó su marido, el militar y dirigente co-

en Francia, del antifascismo a la Guerra Fría (1941-1950). Madrid, Cátedra, 2009. MORENO SECO, M.: “L'exil au féminin: républicaines et antifranquistes en France» en VARGAS, B. (dir.): La Séconde République espagnole en exil en France (1939-1977). Albi, Presses Universitarires de Champollion, 2008, pp. 163-181 y AGUADO HIGÓN, A. y MAESTE MARÍN, R.: «Mujeres Libres en el exilio. Identidad femenina y cultura libertaria», en L'exili cultural de 1939. Seixanta anys després. Valencia, Universitat de València-Biblioteca Valenciana, 2001, vol. 2, pp. 47-70. Para México, vid. DOMíNGUEZ PRATS, P.: Op. Cit., pp. 215-256.

${ }_{16}$ MANGINI, S.: Recuerdos de la Resistencia. La voz de las mujeres en la Guerra Civil española. Barcelona, Península, 1997, p. 192.

17 GREENE, P. V.: «Memoria y militancia: Federica Montseny», Duoda, 10 (1996), pp. 59-71.

18 GRILLO, R.M.: Op. Cit.

19 TAVERA, S.: «La memoria de las vencidas..., p. 217 y DI FEBO, G.: «Memoria e identidad política..., pp. 317-318.

20 PASSERINI, L.: Torino operaia e fascismo. Bari, Laterza, 1984, p. 6 y SCHWARTZ, P.: «Résistante et différence des sexes: bilan et perspectives», Clio. Histoire, Femmes et Sociétés, 1 (1995), pp. 88.

21 PARGA, C.: Antes que sea tarde. Madrid, Compañía Literaria, 1996, p. 17. 
munista Manuel Tagüeña, se observa un mayor grado de intimismo. En todo caso las dos presentan, a diferencia de otras memorias del exilio, muchas experiencias del mundo personal y cotidiano.

Durante la guerra y el exilio, la causa antifranquista impregnó de una aparente uniformidad actitudes y comportamientos, bajo la cual, sin embargo, subyacía una gran complejidad. De esta forma, muchas de las memorias analizadas reflejan la evolución ideológica o política de sus autores/as. Por ejemplo, en los diarios de Manuel Azaña llama la atención, quizá por el propio carácter del texto, más intimista y sin una aparente intencionalidad de adoctrinamiento ${ }^{22}$, la autocaracterización de un personaje muy distinto en su juventud —cuando todavía no ocupa ningún cargo público relevante- y en su madurez, momento en que la defensa de la República ante la guerra se convierte en el móvil de su existencia y cierra el paso a la intimidad. Igualmente la obra de Tagüeña presenta una evolución relacionada con un cambio en su posición ideológica respecto al PCE. Exiliado en varios países el bloque soviético, fue un comunista crítico con la URSS, lo cual se aprecia en unas memorias que pasan de lo político hacia lo más personal y familiar a medida que la distancia con el partido se fue consolidando. Incluso en las monolíticas memorias de Dolores Ibárruri se observan ciertas discontinuidades entre el periodo anterior a la guerra, el conflicto bélico y el exilio. Aunque se muestra bastante reacia a expresar sus emociones personales, la guerra es la etapa en la que más claramente se perfila la figura de la Ibárurri militante, lo cual coincide con su momento de mayor proyección pública.

\section{EL COMPROMISO COMO EJE VITAL}

La política era el elemento común de quienes salieron de España en 1939 y la cultura política del exilio fijó en ellos y ellas determinadas actitudes y comportamientos a través de una serie de autorrepresentaciones recurrentes ${ }^{23}$, que se reafirmaron con la escritura y la reiteración de grandes ideales. En 1931, la República se proyectó como un régimen clave en la modernización del país. Se convirtió así en una «idea-fuerza» ${ }^{24}$ capaz de transformar la realidad material. La confusión y la dispersión reinantes tras el golpe de 1936 provocaron que esas expectativas se difuminaran. En los textos autobiográficos la República aparece como un «paraíso perdido „25. Azaña expresa esa imagen de duelo por la República que pudo ser y no fue incluso desde los primeros momentos de la Guerra Civil, a raíz de las

22 No obstante, Santos Juliá señala que se trata de notas para unas futuras memorias. Así pues, «aunque su yo ande siempre por medio, estos de la República y de la guerra son diarios políticos, no íntimos» (JULIÁ, S.: «Introducción» en AZAÑA, M.: Diarios completos. Monarquía, república, Guerra Civil. Barcelona, Crítica, 2000, pp. XV-XVI).

23 PASSERINI, L.: Torino operaia..., p. 3.

24 VOVELLE, M.: Ideologías y Mentalidades. Barcelona, Ariel, 1995, p. 225.

25 DI FEBO, G.: «Memoria e identidad política..., p. 309. 
muertes de unos presos en la cárcel Modelo de Madrid, violencia que negaba la esencia de la República ${ }^{26}$. A partir de esos momentos las expectativas existentes en torno al advenimiento de una España moderna ya no podían encontrar su contrapunto en la realidad. Los exiliados y exiliadas vivieron el presente pero siempre atentos un futuro inmediato que permitiera el regreso, a su vez ligado al pasado de la guerra. Esta circunstancia explica que la fidelidad a un partido o una ideología ofreciera seguridad en esa difícil coyuntura y permitiera la idealización de la República y la Guerra Civil.

El compromiso con el partido es patente en el relato de Dolores Ibárruri, quien hace hincapié constantemente en la valentía española y en los esfuerzos del PCE por resistir durante el conflicto. Su figura se difumina en la organización política: «la subjetividad queda absorbida por la dimensión ideológica» ${ }^{27}$. No hay apenas alusiones personales, lo cual responde a un elemento presente en muchos de los exiliados: recordar la tragedia del pueblo español, que exigía vivir en un duelo permanente por la legitimidad democrática perdida, manteniendo un compromiso de lucha constante. Quedaba cerrada la puerta a cualquier veleidad que pudiese hacer peligrar una idea que les transcendía. Se trataba de mantener vivo el compromiso con una España republicana que era necesario restaurar a costa de cualquier sacrificio, incluso personal. Ese empeño se convierte en «entrega a una causa que consideraban noble», y que podría «cambiar la España negra, perdida en la noche de los tiempos, por algo diferente, de amor a las gentes, de fraternidad, de posibles nuevas, más igualitarias». Una causa que exigía a sus seguidores «dejar de ser» ${ }^{28}$.

En los testimonios estudiados, destaca el deseo de fijar en el recuerdo, consciente o inconscientemente, tanto las decisiones políticas personales, como las de la agrupación política en la que se militaba, legitimando sus actuaciones. Santiago Carrillo lo indica explícitamente en la presentación de su libro al señalar que aunque en él hay algunas "opiniones autocríticas», también existe «la intención de justificar una actividad» ya que «no se trata sólo de contar lo que uno ha vivido sino de explicar por qué se ha procedido de uno u otro modo, en tal o cual situación „29. Azaña también justifica en sus diarios algunas de sus decisiones políticas durante la guerra. Consciente de las críticas de que era objeto por su aparente distanciamiento de la primera línea política, insiste en que se mantiene en su puesto

${ }^{26}$ AZAÑA, M.: Diarios completos. Monarquía, república, Guerra Civil. Barcelona, Crítica, 2000, p. 1204.

27 DI FEBO, G.: «Memoria e identidad política..., p. 313. Sin embargo, las memorias de su secretaria, escritas mucho más tarde, introducen numerosas alusiones personales y denuncias feministas, ausentes en las de Ibárruri. Vid. FALCÓN, I.: Asalto a los cielos. Mi vida junto a Pasionaria. Madrid, Temas de Hoy, 1996.

28 ARNÁIZ, A.: Retrato hablado de Luisa Julián. Madrid, Compañía Literaria, 1996, p. 134.

29 CARRILLO, S.: Memorias. Barcelona, Planeta, 1993, p. 10. También la anarquista Sara Berenguer insiste en que escribe sobre sus vivencias de la guerra no tanto para dar a conocer su trayectoria personal sino para reivindicar la voluntad colectiva (Entre el sol y la tormenta. Barcelona, Seuba, 1988, p. 12). 
y manifiesta su cansancio y su desilusión por haber sido ignorado ${ }^{30}$. El matrimonio Tagüeña-Parga une a ese deseo de dejar constancia de su resistencia en la Guerra Civil un interés por explicar su disidencia del comunismo durante el exilio. Manuel Tagüeña quiere proporcionar información «a los que sin prejuicios traten de comprender la época agitada de guerras y revoluciones en que mi generación se ha debatido", dedicando el libro a «todos aquellos que en la trágica disyuntiva de la primera mitad del siglo XX supieron vivir y morir dignamente». Carmen Parga afirma igualmente que el objetivo de sus memorias es «recordar a mis nietos y en general a las nuevas generaciones las desgracias, calamidades y tragedias que pueden provocar la irracionalidad y el fanatismo ${ }^{31}$.

La intencionalidad política y militante de las memorias conduce a que el dirigente comunista Gregorio López Raimundo se excuse ante el lector por incluir episodios de su vida que podrían considerarse «probablemente frívolos» e «impropios de un militante comunista seleccionado para asumir responsabilidades de dirección del PSUC en la clandestinidad \$32. Unos episodios que no aparecen en ningún momento en las memorias de Santiago Carrillo porque las «referencias a mi vida personal, íntima, que también la tuve, como todo el mundo (...) no me pertenecen a mí sólo, interesan a otras personas cuya intimidad también tengo el deber de respe$\operatorname{tar}{ }^{33}$. Esta rigidez, que superpone la política a la privacidad en todo momento, es evidente incluso en episodios de una gran intensidad emocional, como el regreso a España después de cuarenta años de exilio. En esa coyuntura Dolores Ibárruri apela a la emoción, aunque rápidamente la sustituye por un discurso político en el que el «suelo patrio», el «pueblo» y «los trabajadores de mi tierra» anulan lo personal ${ }^{34}$.

Aunque se trata de memorias políticas, escritas por dirigentes y militantes políticos, no por literatos, cabe reseñar el pudor y reserva con que relatan sus sentimientos, que se explica por la importancia concedida al compromiso. Tagüeña y Parga en ningún momento indican cuándo se enamoraron ni suelen hablar de su relación. Relatan su boda, en plena Guerra Civil, con pocos detalles y ninguna expresividad: «El 31 de octubre pedí permiso y marché a Madrid a casarme. Carmen Parga aceptó, aunque no tenía noticia previa de mi decisión. (...). A las pocas horas estaba otra vez en la Sierra» ${ }^{35}$. El relato de las hazañas militares deja en un segundo plano su matrimonio, cuya celebración decide él, con una mujer a la que todavía nombra con su apellido, detalle que refuerza la distancia que toma ante la boda. Ella repite el mismo patrón: «Nos casamos en octubre del 36 y yo pasé los

30 AZAÑA, M.: Op. Cit., p. 1242.

31 TAGÜEÑA LACORTE, M.: Testimonio de dos guerras. Barcelona, Planeta, 1978, p. 11 y PARGA, C.: Op. Cit., p. 17.

${ }^{32}$ LÓPEZ RAIMUNDO, G.: Primera clandestinidad. Memorias. La caja de Pandora 2. Barcelona, Antártida/Empuries, 1993, p. 13.

33 CARRILLO, S.: Op. Cit., p. 11.

34 IBÁRRURI, D.: La lucha y la vida (El único camino. Me faltaba España). Barcelona, Planeta, 1985, p. 734.

35 TAGÜEÑA LACORTE, M.: Op. Cit., p. 97. 
tres años de guerra cerca del frente, ayudando a los comisarios con la experiencia de mis anteriores luchas ${ }^{36}$. Ésta es la tónica general de las memorias de ambos. En el momento crítico del fallecimiento de su marido, Carmen Parga prefiere resaltar su figura pública a expresar su dolor por la pérdida, destacando que «afrontó la muerte con el mismo valor con que había afrontado la vida. Se despidió de las niñas y de mí, y nos pidió que no le lloráramos. Se consideraba afortunado de ser superviviente de tantas batallas, en las que había visto morir a tantos hombres» ${ }^{37}$.

Carrillo es otro ejemplo de ello, no sólo por las escasas alusiones a su primera mujer, de la que se separó pronto, sino incluso a la segunda, de quien sólo apunta que trabajaba como su auxiliar desde 1947 y que era «hija de una familia comunista y empezó a militar siendo casi una niña, en el periodo de resistencia en Francia ${ }^{38}$. Teresa Pàmies, destacada integrante de las JSU, también habla poco de sus sentimientos, aunque reconoce que «somiava en una declaració d'amor a l'alçaria del meu romanticisme». Pero el escogido "havía de tenir tots els atributs d'un bon militant» y si pudiera ser que «fos maco» ${ }^{39}$.

Sin embargo, López Raimundo, compañero de Teresa Pàmies, rompiendo con los estereotipos de género, es más prolijo al relatar sus sentimientos amorosos. Describe el momento en que conoció a Teresa como el inicio de «nuestra accidentada relación». Durante el exilio reconoce que «aunque padeció en más de una ocasión comienzos de enamoramiento", nunca los dejó prosperar porque «necesitaba estar libre para salir hacia España a la primera oportunidad», aunque reconocía que el verdadero factor de fondo y decisivo era que «siempre esperé a Teresa ${ }^{40}$. En este aspecto, también Manuel Azaña es menos pudoroso, pues él manifiesta el amor por su esposa. No obstante, lo hace para justificar decisiones políticas, como veremos ${ }^{41}$.

Asimismo, las memorias de Federica Montseny aluden directamente a la ternura que siente por su compañero, Germinal Esgleas. Comenta cómo se enamoró de él, las dificultades familiares que tuvieron que vencer para poder convertirse en pareja, cómo él le declaró su amor desde la cárcel y ella correspondión ${ }^{42}$. El amor loco de entonces «se fue volviendo razonable con el tiempo y con la usura fatal de las ilusiones y los sentimientos. Pero había tantos lazos de afinidad y de ternura entre nosotros, que todo fue resistiendo a los embates y dificultades de la existencia, a los alejamientos y a las cotidianas tentaciones" ${ }^{43}$. Al igual que Carmen

36 PARGA, C.: Op. Cit., p. 40.

37 Idem, p. 168.

38 CARRILLO, S.: Op. Cit., p. 432.

39 PÀMIES, T.: Quan érem refugiats. Barcelona, Dopesa, 1975, pp. 134-135.

40 LÓPEZ RAIMUNDO, G.: Op. Cit., pp. 37 y 84.

41 Sobre la relación de Azaña con su esposa, basada en los cánones más tradicionales, vid. NÚÑEZ PÉREZ, M.G.: «Sentimiento y razón: las mujeres en la vida de Azaña» en ALTED, A., EGIDO, A. y MANCEBO, M.F. (eds.). Manuel Azaña. Pensamiento y acción. Madrid, Alianza, 1996, pp. 167-195.

42 MONTSENY, F.: Mis primeros cuarenta años. Barcelona, Plaza y Janés, 1987, pp. 38, 42 y 49.

43 MONTSENY, F.: Idem..., p. 52. 
Parga, muestra su admiración por su compañero, pero Federica es más expresiva. En la difícil situación del exilio en la Francia ocupada, Esgleas continúa preocupado por mantener la organización y por difundir propaganda política, mientras ella se enfrenta a problemas de supervivencia con la familia su cargo. Por ello, aunque en un principio se siente desconcertada, luego comprenderá la actitud de su compañero:

«PPero qué ocurrencias tiene este hombre! —me decía-. ¡Como si aquí no pasase nada y no tuviésemos a la Gestapo sobre los talones! ¡Qué forma más elegante tiene de ayudarme a salir de este berenjenal! Después, más serena, comprendía y admiraba el sentido tenaz y responsable de organización de Germinal. (...) Para él (...) lo fundamental, lo permanente era la organización, que debía mantenerse y sobrevivir a todo ${ }^{44}$.

La supeditación de la vida privada a la misión política conduce en ocasiones a adoptar decisiones que afectan a familiares más directos, como hijos o padres. Carrillo es un caso extremo, como se observa en el distinto tratamiento que ofrece de dos noticias terribles que le comunican a la vez, la muerte de su madre y la «traición» de su padre, quien había apoyado el golpe de Casado:

«Yo quería mucho a mi madre. Era una mujer muy sencilla, que se había sacrificado por sus hijos y su marido (...) En otro momento esta sola noticia me hubiera producido una gran conmoción; sin embargo en aquél me dolía aún más agudamente la que consideraba traición de mi padre. Recuerdo que me eché a llorar como un crío, como no lo había hecho desde niño, y como no lo haría más en mi vida (...) Yo, que había estado siempre tan orgulloso de él (...) No podía entenderlo (...) Lo grave es que aquello no era una simple diferencia política; aquello costaba sangre, mucha sangre y de la de mis mejores amigos; era una Guerra Civil dentro del campo republicano. ${ }^{45}$

En el caso de Teresa Pàmies, el grado de compromiso político también fue muy importante. En las vivencias personales que relata en sus obras se presenta como una mujer totalmente íntegra y comprometida por encima de su condición de madre. En uno de los pasajes de Gent del meu exili en el que relata su regreso a Europa desde México con su hijo, reconoce que «el desfici del retorn a Europa, la por de perdre una ocasió 'única', la inexperiencia i la pasió política, pesaren més que el sentit comú» al emprender un viaje en unas condiciones muy duras para un bebé de tres meses ${ }^{46}$.

En la misma tesitura, Aurora Arnáiz se expresa en términos muy similares. Perteneciente a las Juventudes Socialistas, tras la guerra, y con documentación falsa atravesó el país con destino a Francia y posteriormente a México, nación que la acogió en su largo exilio. La integridad política es una constante en la obra incluso

\footnotetext{
44 MONTSENY, F.: Seis años de mi vida, Barcelona: Galba, 1978, pp. 115-116.

45 CARRILLO, S.: Op. Cit., pp. 299-301.

46 PÀMIES, T.: Gent del meu exili. Barcelona, Galba, 1975, p. 56.
} 
ante la maternidad. En los momentos difíciles de la huida, ante la disyuntiva de enviar a su hijo al extranjero, renuncia a hacerlo al pensar en los demás niños que no podrían «disfrutar de un privilegio como ese " 47 . En este sentido, el estereotipo de la rebelde, recurrente en muchas autobiografías de mujeres, no tendría como objetivo primordial la descripción de comportamientos reales, sino que serviría para encuadrar un rol alegórico ${ }^{48}$.

En sus memorias Carmen Parga habla con cariño de sus padres, pero también revela cómo algunas circunstancias críticas le impidieron abandonarse al dolor; en este caso, la distancia respecto a la muerte de los progenitores obedece a la necesidad de sobrevivir. Cuando murió su padre, en plena Segunda Guerra Mundial, afirma que fue uno de los peores días de su vida: «Triste es decirlo, pero la muerte de mi padre aligeró nuestra situación, no sólo porque era una boca menos, sino, y sobre todo, porque sus escasas pertenencias pasaron a ser codiciadas monedas de cambio", que permitieron dar de comer al resto de la familia ${ }^{49}$. En consecuencia, se hace necesario tener en cuenta el contexto político y humano en que se encuentran los exiliados y exiliadas y la evolución en su propia biografía, que en ocasiones difumina la prioridad del compromiso para dar cabida a los sentimientos. «Entonces [en la Guerra Civil] como a todo el mundo me dominaba un solo deseo: vencer. Ahora [en la Segunda Guerra Mundial] pensaba solamente en cómo sobrevivir ${ }^{50}$. Tanto ella como su marido describen largamente las dificultades que experimentaron durante la Guerra Mundial en la URSS, el hacinamiento de las viviendas, el mercado negro para atenuar el hambre o las estrategias para evitar la propagación de enfermedades. Pero, él, que ocupó un cargo de mayor responsabilidad en el partido, alude con mayor frecuencia a la situación política del momento y, en particular, a la tensión que vivieron por las purgas políticas.

Algo similar ocurre con Montseny, cuando, a pesar de la ternura que muestra por su padre, alude a la enfermedad de éste, que en ocasiones lo convertía en una carga, ya que en los momentos críticos de la clandestinidad en la Francia ocupada ponía en peligro a la familia a causa de su demencia senil: « Qué horrible calvario para él y para nosotras! ${ }^{51}$. Esta dirigente anarquista expresa con claridad las dificultades de hacer compatible una vida política activa y una vida familiar. Ante la separación de su hija, debido a sus actividades políticas, afirma: «No quería (...) que la maternidad fuese para mí una barrera en mi vida de luchadora y de militante, como no había querido que el amor tampoco lo fuese. Era necesario soportar el desgarro de la separación ${ }^{52}$.

47 ARNÁlZ, A.: Op. Cit., p. 112.

48 PASSERINI, L.: «Women's personal narratives. Myths, Experiences and Emotions», en The Personal Narratives Group (ed.): Interpreting Women's Lives. Feminism Theory and Personal Narratives, Bloomington and Indianapolis, Indiana University Press, 1989, pp. 189-197.

49 PARGA, C.: Op. Cit., pp. 82-83.

50 Idem, pp. 62-63.

51 MONTSENY, F.: Seis años de mi vida...., p. 128.

52 MONTSENY, F.: Mis primeros cuarenta años..., p. 78. 
En suma, la interrelación entre política y privacidad es constante en hombres y mujeres, pero en muchos casos no se considera relevante dejar testimonio o conceder importancia a lo privado en aras del compromiso.

\section{LA PRIVACIDAD IRRUMPE EN LO PÚBLICO}

En estas memorias políticas, escritas para dejar constancia de una vida entregada a la lucha, las vivencias y sentimientos personales aparecen en determinados momentos importantes e incluso en ocasiones provocan rupturas con el compromiso político. El alejamiento del matrimonio Parga-Tagüeña del comunismo estalinista muestra esta dualidad. Mientras él decide abandonar el comunismo oficial tras reflexionar sobre las purgas y verse afectado por ellas, Parga lo hizo años antes a causa del suicidio de su cuñada, una joven soviética marcada por la represión estalinista:

«Fue para mí un día terrible y una noche espantosa. (...) Aparte del dolor de su muerte, me sentía sucia, cómplice de todos los crímenes que en el mundo se estaban llevando a cabo, con el pretexto de ayudar a los pueblos a 'liberarse' (...). Cuando a la mañana siguiente me levanté, le comuniqué a mi marido que aquella noche había dejado de ser comunista. Tardé más de diez años en poder decirlo en voz alta, libremente, sin miedo»53.

Los relatos de vida analizados reflejan diversas discontinuidades, que a su vez giran en torno a estereotipos muy marcados. Aunque en apariencia rompen con la ortodoxia que se quiere transmitir desde el punto de vista político, siguen reproduciendo convencionalismos muy arraigados en la moral de la época: la madre abnegada, la doble moral sexual o la sensibilidad «femenina» frente a la responsabilidad «masculina».

Las diferencias entre hombres y mujeres afloran especialmente al abordar la maternidad y la paternidad. De acuerdo con el discurso que supedita la vida privada a la política, la relación con los hijos debería ser un tema poco tratado en las memorias. Así sucede generalmente en el caso de las masculinas, como las de Carrillo, quien exhibe una notable frialdad frente a la paternidad, ajustándose a la tradicional división de roles femeninos y masculinos que asigna a las mujeres en exclusiva el cuidado de los hijos. Al terminar la guerra, su compañera y su hija Aurora quedaron en España, en el puerto de Alicante, y pasaron por el campo de concentración de Albatera. La deficiente alimentación y otras penalidades resintieron la salud de la niña. En 1944 Carrillo emprendió un viaje a América Latina, dejando a su hija muy enferma «en un hospital de Moscú; me despedí de ella convencido de que no volvería a verla, como aconteció; era una de las víctimas de nuestra guerra y de los campos de concentración de Franco». No expresa dolor por la

53 PARGA, C.: Op. Cit., pp. 95-96. 
muerte de la niña, sino que la convierte en parte de su actividad política, en víctima de la dictadura contra la que lucha. La única concesión que hace a sus sentimientos paternales aparece con motivo del nacimiento de su primer hijo varón en la clandestinidad, en Francia: «Es uno de los días más extraordinarios de mi vida a pesar de la razzia que estamos sufriendo. Mi mayor ilusión desde hacía tiempo era tener hijos. (...) (En sucesivos años, cuando nazcan Pepe y Jorge, me las arreglaré, pese a la clandestinidad, para registrarles legalmente. Ser su padre ha sido una de las mayores felicidades de mi vida)»"54. No vuelve a hablar de sus hijos.

Sin embargo, y aquí la perspectiva de género es fundamental, no sucede lo mismo con las memorias femeninas, que reproducen en general el estereotipo de la madre abnegada ${ }^{55}$. Durante la guerra, Federica Montseny intentó hacer compatible su cargo como ministra con la dedicación a su hija, yendo a visitarla con frecuencia a Barcelona ${ }^{56}$. Aunque abortó en una ocasión y reconoce que tuvo embarazos no deseados, muestra con frecuencia una gran ternura hacia sus hijos. Con ellos compartió el exilio en Francia, en circunstancias muy difíciles. Por ellos sufrió y gracias a ellos encontró las fuerzas necesarias para continuar resistiendo a la persecución nazi, como si de una «Madre Coraje» se tratara ${ }^{57}$. Comenta en un pasaje: «Sólo silencio, soledad, desamparo total y absoluto. Pero en aquel instante, reduciendo al hoy inmediato toda perspectiva, me sentí feliz pensando que mis hijos estaban vivos, que dormían dichosos y tranquilos, en un lecho bien blando. Mañana, ya veríamos. Delante nuestro había muchos caminos por recorrer, muchos días que vivir» ${ }^{58}$.

De la misma forma, Dolores Ibárruri, que es absolutamente hermética en otras cuestiones privadas, expresa profundos sentimientos maternales al hablar de sus hijos y los proyecta hacia otros exiliados y compañeros. Este hecho se observa en especial cuando rememora la muerte de su hijo Rubén, como soldado del ejército soviético en la Segunda Guerra Mundial. Aunque alude a la heroicidad de su hijo, en ocasiones revela su desgarro: «¿Cómo hablar de mi dolor? Era el dolor, el más hondo de todos los dolores, el de una madre que pierde a su hijo. Y era mi único hijo varón. Tan sólo me quedaba Amaya, de los seis que traje al mundo "59. La expresión de sus sentimientos reales proyecta la imagen de maternidad entregada y dolorosa, lo cual refuerza su figura política a la vez que la encuadra en la concepción tradicional de la identidad femenina. La muerte de su hijo le convirtió de forma definitiva en símbolo de ofrecimiento y sufrimiento por la causa del pueblo ${ }^{60}$.

54 CARRILO, S.: Op. Cit., pp. 337 y 432.

55 MORENO SECO, M. y MIRA ABAD, A.: «Motherhood(s) and Memoirs Written by Women in the Spanish Exile» en CAPORALE BIZZINI, S. (ed.): Narrating Motherhood(s), Breaking the Silence: Other Mothers, Other Voices. Bern-New York-Oxford, Peter Lang, 2006, pp. 51-75.

56 MONTSENY, F.: Mis primeros cuarenta años..., p. 118.

57 TAVERA, S.: Federica Montseny. La indomable. Madrid, Temas de hoy, 2005, p. 252.

58 MONTSENY, F.: Mis primeros cuarenta años..., p. 170.

59 IBÁRRURI, D.: Op. Cit., p. 542.

60 CRUZ, R.: Pasionaria. Dolores Ibárruri, historia y símbolo. Madrid, Biblioteca Nueva, 1999, p. 157. 
Puede hablarse, en este sentido, de la construcción de un mito en torno a Pasionaria, como madre sufriente y «Dolorosa laica»61: «Madre. Así la llaman los niños, las mujeres, hasta las viejecitas que asisten a la Conferencia, porque el amor que Dolores siente por las mujeres del pueblo es sólo comparable al amor noble de madre trabajadora»62. Su propia autobiografía se vio afectada por la leyenda creada en torno a ella ${ }^{63}$. En Me faltaba España, Ibárruri afirmaba: «en cierto modo también eran familia mía los españoles exiliados, a quienes hube de ayudar a normalizar su vida»64. Era la madre simbólica de los soldados que murieron en España y defendiendo la URSS, y también la madre de los militantes del partido comunista ${ }^{65}$. Durante la guerra, «la imagen pública que de ella se proyectó fue la de una mujer en la que se expresaban a la vez el sufrimiento y el valor de todo el pueblo español» 66 . Por tanto, no sólo es mostrada como madre, sino como símbolo de las virtudes del pueblo español: rebeldía, lucha por la justicia, sufrimiento y sacrificio - representados por las ropas negras que siempre vistió, manifestando un eterno duelo por la causa perdida - ${ }^{67}$. Según Arnáiz, Dolores «seguía siendo el símbolo de la resistencia» para los exiliados españoles, por tanto aunque sus vidas discurrieran por cauces diversos ese símbolo se instituyó en guía de comportamientos y valores ${ }^{68}$.

Algunas memorias rompen estos estereotipos y presentan una paternidad muy atenta al devenir de los hijos o de los niños de la familia. Es el caso de Azaña, quien no tuvo hijos, pero expresa ternura y preocupación por sus sobrinos: «Ha pasado unos días con nosotros mi sobrina Ana. (...) El niño que le ha quedado es monísimo, listo, fuerte y muy sociable. Aunque sólo cuenta veintiséis meses, habla, discurre y juega como si tuviera cuatro años. Nos hemos hecho muy amigotes. Último vástago de la familia. ¿Qué será de él?»69. También Tagüeña reconoce que «la vida de nuestra familia giraba en torno a mi hija, todo lo sacrificábamos para que sintiera lo menos posible las privaciones que sufríamos ${ }^{70}$. Habla con orgullo de los progresos educativos de sus dos hijas y recuerda en sus memorias que en el viaje de huida de Checoslovaquia «fui quizá demasiado duro en mis restricciones y siempre me arrepentiré de no haber dejado que Julita cargara con su oso de peluche. No lo olvidó nunca, aunque tratamos de sustituirlo, tan pronto como nos fue posible. Tuvo varios osos pero ninguno 'como aquél' $\gg{ }^{71}$.

61 AVILÉS, J.: Pasionaria. La mujer y el mito. Barcelona, Plaza y Janés, 2005, p. 113.

62 FALCÓN, I.: «Dolores», Frente Rojo, 2-XI-1937. Sobre el culto a la personalidad de Ibárruri, remitimos a CRUZ, R.: Op. Cit., pp. 171-177 y AVILÉS, J.: Op. Cit., p. 188.

${ }^{63}$ MANGINI, S.: «Memories of Resistance..., p. 175.

64 IBÁRRURI, D.: Op. Cit., p. 487.

65 CRUZ, R.: Op. Cit., pp. 190-191.

${ }^{66}$ AVILÉS, J.: Op. Cit., p. 29.

${ }^{67}$ CRUZ, R.: Op. Cit., pp. 131-137.

68 ARNÁlZ, A.: Op. Cit., p. 136.

69 AZAÑA, M.: Op. Cit., p. 1162.

70 TAGÜEÑA LACORTE, M.: Op. Cit., p. 287.

71 Idem, p. 415. 
Junto a la maternidad y la paternidad, el relato de las experiencias extramatrimoniales o las aventuras amorosas puede observarse desde varias perspectivas. Por una parte son situaciones que, si bien rompen con el estereotipo del «buen» comunista o republicano, en el fondo reproducen el modelo más tradicional de la doble moral para hombres y mujeres. Durante su estancia en Brasil, en los meses de espera para que le fuera concedido el visado de entrada a Francia, López Raimundo conoció a una joven activista de la Asociación de Amigos de la República Española, con quien inició una relación, teniendo ambos conciencia de que era pasajera y que «lo principal fue siempre la actividad política» ${ }^{72}$. En cambio, Dolores Ibárruri silenció por completo en sus memorias la prolongada relación que mantuvo, después de separarse de su marido, con Francisco Antón, un dirigente del PCE bastantes años más joven que ella, lo cual demuestra «her desire to appear politically correct ${ }^{73}$. Así salvaguardaba no sólo su imagen como dirigente comunista, sino también como mujer, en una formación política en la cual se censuraba aquello que en un hombre se hubiera considerado normal ${ }^{74}$. Como bien señala Cruz, «los críticos comunistas a estas respuestas humanas otorgaron más peso a los valores tradicionales de la moral cristiana que a las aptitudes políticas de los dirigentes " ${ }^{75}$. Según Carrillo, los ataques que recibió fueron tan duros que Ibárruri renunció a toda vida personal, rompió dicha relación y se dedicó en exclusiva al partido ${ }^{76}$.

Por último, en las memorias se reproduce el estereotipo de la sensibilidad femenina, la mayor capacidad de comprensión de las mujeres ante el sufrimiento ajeno. No obstante, Ibárruri no se ajusta a ello cuando expresa una gran dureza frente a intelectuales como Fernando de los Ríos, quien reflexionaba dolorido ante los espantos de la guerra: “¿QQuién hubiera podido imaginarse que yo [De los Ríos] había de encontrarme en el trance de comprar armas para que los hombres se maten?' Yo [lbárruri] le miraba, le miraba, no sabiendo si indignarme o reírme, al tiempo que pensaba: '¿Quién habrá sido el idiota que encarga estos asuntos a hermanas de la caridad?'»77.

En cambio, Azaña muestra su consternación ante el uso de la violencia, identificándose precisamente con Fernando de los Ríos. En un encuentro con éste, «me dice cuánto se ha acordado de mí, y cree comprender lo que estoy pasando.

72 LÓPEZ RAIMUNDO, G.: Op. Cit., pp. 83-85.

73 MANGINI, S.: «Memories of Resistance..., p. 176.

74 AVILÉS, J.: Op. Cit., pp. 123-124. Así lo admiten, tiempo después, Carrillo y Tagüeña. El primero comenta la discreción con que mantuvieron sus relaciones, aunque reconoce que existía cierta envidia y se atribuía el ascenso de Antón dentro del partido a su relación personal, cuando en realidad, en su opinión, se vio perturbada y hasta arruinada por esa causa (CARRILLO, S.: Op. Cit., p. 261). Tagüeña relaciona las maledicencias a la lucha por la sucesión dentro del PCE, en que «Dolores empezó a ser objeto de toda clase de epítetos despectivos, que subían de tono cuando se referían a Francisco Antón, al que llamaban 'Godoy' en recuerdo del favorito de la esposa de Carlos IV » (TAGÜEÑA LACORTE, M.: Op. Cit., p. 285).

75 CRUZ, R.: Op. Cit., p. 152.

76 CARRILLO, S.: Op. Cit., p. 358.

77 IBÁRRURI, D.: Op. Cit., pp. 306-307. 
No lo dudo. Mejor que casi todos lo comprenderá él, por ciertas analogías de formación intelectual, que apenas ningún otro político tiene conmigo»78. Es recurrente en sus memorias la expresión de angustia y dudas por la guerra ${ }^{79}$. En un despacho con Negrín, éste comenta, aludiendo a un ministro, «'Si resultara condenado un hijo suyo, o su madre, también los fusilaría, aunque se pegase un tiro después...' (Lo mismo dicen y hacen los del otro lado. Todos iguales. ¡Qué raza! ¿Pertenezco a otra?)». Se sabe un intelectual en todo momento; construye su imagen como tal, insistiendo en que no siente deseos de venganza, y justifica su aparente apatía como un signo de sabiduría ${ }^{80}$. También Tagüeña manifiesta dolor por la separación de sus compañeros y amigos de Checoslovaquia, cuando decidió huir con su familia del bloque comunista. El día de su marcha mucha gente se reunió en la estación para despedirles; todos estaban muy tristes porque «se rompían definitivamente fuertes lazos de esos que sólo se atan en épocas duras». Cuando el avión en el que embarcaron sobrevolaba Alemania occidental, dejando atrás el telón de acero, «en ese momento, cuando no había ya nada que temer, me sentí profundamente deprimido ${ }^{81}$.

Una posición muy diferente expresa Carrillo, pues ante los horrores de la guerra recuerda la necesidad de actuar, justificando la trayectoria del PCE en el conflicto:

«Cuando uno está alejado en el tiempo y en la distancia de una guerra - y en esta época hay muchas - cabe la posibilidad de una reflexión puramente humana, dolida por la desaparición de vidas sin diferencias el campo en que caen. Pero cuando tú estás inmerso en esa guerra, convencido de que defiendes una causa justa, no sientes la pérdida de vidas del enemigo como sientes la de tus correligionarios, no; desgraciadamente para que venzan los tuyos tienen que caer los otros. Es el sinsentido de todas las guerras y desgraciadamente seguirá siéndolo mientras haya guerras. No trato de justificarme ni de busca atenuantes ${ }^{82}$.

Frente a la sensibilidad «femenina», que no obstante algunos varones demuestran en ciertas ocasiones, el sentido de responsabilidad «masculino", como cabeza de familia, aparece de una forma u otra en los políticos analizados, que son los que toman decisiones críticas que afectan a todo el núcleo familiar en situaciones muy difíciles. El uso de la primera persona es sintomático. Después de la guerra, Carrillo se reúne con su mujer y su hija en Francia, y marchan juntos a la URSS, cruzando la Alemania nazi clandestinamente. De este viaje habla siempre en singular y concluye que, después de la guerra y la clandestinidad, llegar a la URSS «significaba sentirme plenamente seguro por primera vez» ${ }^{83}$. En el mismo

78 AZAÑA, M.: Op. Cit., p. 992.

79 ARÓSTEGUI, J.: «Manuel Azaña y la Guerra Civil como tragedia» en ALTED, A., EGIDO, A. y MANCEBO, M.F. (eds.): Manuel Azaña. Pensamiento y acción. Madrid, Alianza, 1996, pp. $295-307$.

80 AZAÑA, M.: Op. Cit., pp. 1235 y 1006-1007.

81 TAGÜEÑA LACORTE, M.: Op. Cit., pp. 414 y 417.

82 CARRILLO, S.: Op. Cit., p. 209.

83 Idem, p. 322. 
sentido, mientras que Tagüeña habla desde el «yo» con frecuencia, Parga utiliza más el plural «nosotros», aludiendo a la pareja o la familia. La comprometida decisión del matrimonio Parga-Tagüeña de huir del bloque soviético, que pudo haber supuesto años de cárcel e incluso la vida, no fue producto de una decisión común, sino exclusivamente de una resolución de él. Como ella relata, «una mañana, sin decir jagua va!, se levantó decidido a iniciar las gestiones para trasladarnos a México " ${ }^{84}$. En otro momento delicado, en que se sienten amenazados por sus simpatías hacia el régimen de Tito, cuando éste cae en desgracia ante la URSS, ella afirma: «Tagüeña hizo el Quijote muchas veces, pero nunca como entonces en que estando completamente al lado de los yugoslavos, sabiendo que corría muchos riesgos, aceptó la decisión del Partido. Y yo, como nunca, hice de Sancho Panza, siguiéndolo» ${ }^{85}$. Por su parte, Azaña, ante la posibilidad de que la residencia donde vivía con su mujer sufriera el ataque del enemigo, dudaba si huir o quedarse, ante el miedo de exponer a su mujer a algún peligro:

«Su vida me parecía sagrada, entregada a mi custodia y protección; y hubiese querido ponerla con mi amor donde no la alcanzasen las intemperies. Nunca ha influido mi mujer en ningún acto político mío (...).Y, en realidad, ahora tampoco me influyó, porque me resolví a lo que hicimos creyendo que era lo mejor, con su anticipado consentimiento.» 86

Sin embargo, este supuesto sentido de responsabilidad atribuido a los varones es desempeñado en el caso de la pareja Esgleas-Montseny por ella, quien en los primeros años del exilio se encargó de la supervivencia familiar, mientras su compañero estaba encarcelado o centrado en la vida organizativa de la CNT. De hecho, en los primeros momentos del exilio, las familias con frecuencia dependieron sobre todo del trabajo de las mujeres, trastocando en ocasiones las relaciones de poder en las parejas ${ }^{87}$.

\section{CONCLUSIONES}

En general, en la mayoría de los exiliados y exiliadas, el sacrificio, la pérdida y el dolor por la vida que dejaban atrás se convirtieron en un referente moral que les obligaba a un comportamiento íntegro. Se retomaba el «ideal de virtud» del republicanismo y del pensamiento progresista, que no sólo implicaba la identificación con una idea política, sino también actuar en consonancia con ella. El frente republicano quería presentarse ante la sociedad como una opción política y social moralmente honesta frente a los tópicos reaccionaros, tendentes a distorsionar la figura del político o la política de izquierdas asimilándolos al agitador, al maleante

\footnotetext{
84 TAGÜEÑA LACORTE, M.: Op. Cit., p. 405 y PARGA, C.: Op. Cit., p. 151.

85 PARGA, C.: Op. Cit., p. 120.

AZAÑA, M.: Op. Cit., pp. 953-954.

7 DOMÍNGUEZ PRATS, P.: Op. Cit., pp. 91-92 y 149.
} 
0 al ser depravado ${ }^{88}$. Aunque este mensaje de integridad, visible en todas las facetas de la vida, no llegará a la España de la posguerra, sí se convirtió en guía moral para el exilio.

La moral y sobre todo la responsabilidad de conservar el legado republicano formaban parte de ese sistema de valores que rodeaba a los exiliados y exiliadas, encargados en su diáspora de llevar y transmitir «la auténtica hispanidad imperial, con lo más positivo de las raíces latinas: la responsabilidad, la honradez, el sentido ancestral de la integración familiar y social, el amor al semejante. En una palabra: la ética» ${ }^{89}$. Vilar señala en este sentido que «el talante ético del expatriado (...) suele ser irreprochable ${ }^{90}$. Es precisamente éste uno de los elementos que diluyen las diferencias entre las memorias de hombres y mujeres, ya que ambos desean ofrecer una imagen de rectitud moral, un «querer ser» que debía ajustarse en lo posible a la realidad.

Paradójicamente, a pesar de que eran progresistas, con frecuencia seguían prevaleciendo los convencionalismos de la sociedad burguesa. Es un elemento que podemos constatar en hombres y mujeres, aunque ellas, en su condición de madres, lo expresan en mayor medida. En algunas mujeres, puede decirse que a las viejas directrices morales en torno a la maternidad, como elemento que las definía, se unían la lucha política y los proyectos de regeneración social, lo cual podía crear conflictos entre la identidad normativa y la subjetiva. En general predominaba el estereotipo de la «buena madre» que quería mostrarse ejemplar. En estas mujeres observamos que junto a la rectitud moral y a su faceta maternal se unía la importancia simbólica que adquiere la imagen de la rebelde. Mancebo afirma que el exilio enfrentó a todas mujeres, incluso a las más politizadas, a «una situación límite, en la que prevaleció su instinto de conservación y, especialmente, la protección y defensa de sus hijos, sus mayores y, en definitiva, de la familia»" Sin embargo, las mujeres con responsabilidades políticas no se ajustaron al modelo femenino que giraba en torno al hogar. Las memorias de Ibárruri proyectan precisamente la «imagen adecuada de una gran dirigente revolucionaria»92, alejado del ideal de la domesticidad.

${ }^{88}$ En este sentido Dolores lbárruri comenta en sus memorias con ironía la imagen terrorífica que se había creado sobre ella. En una ocasión llegó a sus oídos la conversación de unos soldados franquistas hechos prisioneros, que sin conocerla hablaban «de los crímenes que había cometido, de su crueldad para con los prisioneros, especialmente para con los curas y monjas» porque en realidad esa «fiera», «no es española», no es una mujer sino «una marimacho» (IBÁRRURI, D.: Op. Cit., p. 399). Sobre la crítica moral y política del franquismo a hombres y mujeres vinculadas a la República, vid. RODRÍGUEZ LÓPEZ, S.: «Mujeres perversas. La caricaturización femenina como expresión de poder entre la Guerra Civil y el franquismo", Asparkía, 16 (2005), pp. 177-198 y SEVILLANO, F.: Rojos. La representación del enemigo en la Guerra Civil. Madrid, Alianza, 2007.

89 ARNÁlZ, A.: Op. Cit., p. 237.

90 VILAR, J.B.: La España del Exilio. Las emigraciones políticas españolas en los siglos XIX y XX. Madrid, Síntesis, 2006, p. 19.

91 MANCEBO, M.F.: La España de los exilios. Valencia, Universitat de València, 2008, p. 159.

92 AVILÉS, J.: Op. Cit., p. 35. 
En suma, puede afirmarse que de acuerdo con la hipótesis planteada en la introducción, los relatos de vida analizados muestran con claridad que la vida y la política son dos caras de la misma moneda. Lo público y lo privado se confunden continuamente, poniendo en cuestión la división de esferas impuesta desde el siglo XIX a las relaciones de género. En este sentido, Ana Aguado cuestiona «la falsa dicotomía entre 'público' y 'privado', que en la realidad histórica no es sino interacción y reforzamiento mutuo, en el sentido de que en las experiencias y prácticas históricas no sólo es un hecho que lo privado es político, sino también que lo político está fuertemente impregnado de lo que supuestamente es privado" ${ }^{93}$.

En la construcción y proyección de la imagen de los políticas y políticas que se exiliaron, la línea profesional e ideológica se entrecruzó con la línea vital, permitiendo que en ocasiones afloraran sentimientos más allá de los estereotipos de género. Las dudas, los miedos, la culpabilidad, el arrepentimiento o el amor materno y paterno-filial aparecen con frecuencia en los textos, aunque siempre en torno al hilo conductor de una coherencia política y personal.

${ }^{93}$ AGUADO, A.: «Las relaciones de género y la nueva historia social. Identidad social y prácticas culturales» en El siglo XX. Balance y perspectivas. Valencia, Fundación Cañada Blanch-Universitat de València, 2000, p. 162. 